DOI: $10.1515 /$ plass-2018-0015

\author{
Hossein Askari ${ }^{1 *}$, Seiyed Kamal Kazemitabar ${ }^{1}$, Hamid Najafi Zarrini ${ }^{1}$, \\ Mohammd Hossein Saberi ${ }^{2}$ \\ ${ }^{1}$ Plant Breeding Sari University of Agricultural Sciences and Natural Resources, Sari, Iran; \\ ${ }^{2}$ Associ. Prof. Provincial Research Center of Khorasan Jonobi, Birjand, Iran; \\ *corresponding author email: hmss_askari@yahoo.com

\section{ASSESSMENT OF TOLERANCE AND STABILITY IN BARLEY (HORDEUM \\ VULGARE L.) GENOTYPES AT EARLY SEEDLING GROWTH STAGE UNDER SALINE CONDITION}

\begin{abstract}
This study was performed to assess several indices for identifying genotypes at early growth stage with the best performance in salinity conditions. In order to evaluate the biomass production of barley genotypes in different levels of salt conditions, an experiment was conducted as factorial arrangement with a completely randomized design with 3 replications. The effect of salinity treatments was studied through an analysis of the dry matter production, yielding results that show significant differences among genotypes. The majority of used tolerance indices indicated that ESBYTM8910, 4 Shori and MBS8715 were the best barley genotypes showing the highest stress resistance for the greatest $\mathrm{NaCl}$ concentration. Based on used stability parameters the genotypes MBS8712 and Jo torsh were the most phenotypically stable. Result of cluster analysis revealed that tolerant genotypes showed the least stability based on mostly of stability parameters. In general, results showed the WB7910, ESBYTM8910 and MBS8715 genotypes appeared better than others across the salinity levels.
\end{abstract}

Key words barley, salt tolerance, stability, tolerance indices

List of abbreviations

ANOVA = Analysis of variance;
$\mathrm{CRD}=$ Complete randomized design;
$\mathrm{GMP}=$ Geometric mean productivity;
$\mathrm{GEI}=$ Genotype*environment interaction;
$\mathrm{MP}=$ Mean productivity;

$\mathrm{SSI}=$ Stress susceptibility index;

STI $=$ Stress tolerance index;

$\mathrm{TOL}=$ Stress tolerance;

Communicated by Grzegorz Żurek 


\section{INTRODUCTION}

It is estimated that about $15 \%$ of the total land area of the world has been degraded by salinization and soil erosion, which are among the major causes of desertification (Mariangela Montemurro, 2015). Abiotic stresses such as drought and salinity are responsible for significant yield losses in barley on a worldwide scale, and yet under severe stress conditions, barley remains to be an important crop used as feed for animals, malt and human food (Katerji et al., 2006). The establishment stage of the crop consists of three parts: germination, emergence and early seedling growth; that are particularly sensitive to substrate salinity (Saboora et al., 2006).

Germination and seedling growth under saline environment are the screening criteria which are widely used to select the salt tolerance genotype. As for better cropping highest plant population is required, which is only possible if seed germination is satisfactory under saline conditions (Nasser et al., 2001). However, the effectiveness of such screens varies but the main emphasis seems to be in balance with a controlled environment, so that the screening techniques are reliable, against the uncertainty of variation in natural conditions in the field (Bernardo et al., 2006).

Salinity impairs seed germination, reduces nodule formation, retards plant development and reduces crop yield (Muhammad et al., 2006). Several researchers have reported the selection of barley genotypes under favourable conditions (Betran et al., 2003). Selection by the aim of stress condition has been highly suggested too. A number of researchers have preferred the mid-way and believe in selection under both favorable and stress conditions (Ashraf et al., 2015). Several selection criteria, such as stress tolerance and mean productivity (Rosielle and Hambling, 1981), stress susceptibility index (Fisher and Maurer, 1978), geometric mean productivity and stress tolerance index (Fernandez, 1992) have been proposed as indicators to identify genotypes with better stress tolerance. Giancarla et al. (2012) in evaluating the ability of drought tolerance indices to identify tolerant barley genotypes under laboratory conditions stated these indices may be screened for indirect selection of drought tolerance in the initial stage of the crop growth. As a result, three main strategies have been recognized that plants use to cope with stress: (i) specialization, the genotype is adapted to the specific environment; (ii) generalization, the genotype has moderate suitability in most environments; and (iii) phenotypic plasticity, signals from the environment interact with the genotype and stimulate the production of alternative phenotypes (Fritsche and Borém, 2005).

Phenotypic plasticity is high when compared to the yield stability (Bradshow, 2006). Thus, low plasticity (or high stability) is not always a desirable characteristic because tolerant genotypes generally have moderate productivity, even under ideal growing conditions (Fritsche and Borém, 2005). The economic significance of stability for the cultivation of a genotype was first identified by Roemer (1917), who used the variance across environments as a parameter for yield stability. Using the dynamic concept of stability, Wricke's model (1962) is the simplest method to evaluate the stability. Wricke suggested the ecovalence $\left(\mathrm{W}^{2}{ }_{\mathrm{i}}\right)$ concept as the ratio of the interaction sum of squares contributed by each 
genotype to the $G^{*} E$ interaction sum of squares. Shukla (1972) proposed the variance component of each genotype across environments as another relevant measure of phenotypic stability. It measures stability rather than performance.

The regression coefficient was introduced by Finly and Wilkinson (1963) as the regression of the mean of $i^{\text {th }}$ genotype in jth environment on the mean performance of all genotypes in that environment. A criticism of the use of simple linear regression models is based on the potential non linear pattern of genotype responses to environmental variation. The first proposal to solve this deficiency was presented by Verma et al. (1978). They separated the environments into two groups (favorable and unfavorable) and fit a simple linear regression model separately to each part. Eberhart and Russell (1966) suggested using the mean of squared deviation from regression as a measure for stability and a stable genotype is the one has a small deviation from regression mean squares.

The objective of this research was to evaluate the tolerance and phenotypic stability barley genotypes at early growth stage, based on dry matter production, which allows a quick and easy-to-measure screening tool for genotypic differences in salinity tolerance.

\section{MATERIALS AND METHOD}

The material used for this study comprised 9 barley promising lines and cultivars i.e.:

$\begin{array}{llll}\text { STW82153 } & \text { (A), } & \text { WB7910 } & \text { (F), } \\ \text { MBS8712 } & \text { (B), } & \text { Valfajr } & \text { (G), } \\ \text { ESBYTM8910 } & \text { (C), } & \text { MBS8715 } & \text { (H) } \\ \text { 4 Shori } & \text { (D), } & \text { Jo torsh } & \text { (I). } \\ 5 \text { Shori } & \text { (E), } & & \end{array}$

Germination tests were carried out at 5 levels of electrical conductivities $\left(\mathrm{ds} \times \mathrm{m}^{-1}\right)$ :

$\begin{array}{llllll}\text { S1 (control) } & =4.5, & \text { S4 } & = & 13.5, \\ \text { S2 } & =7.5, & \text { S5 } & = & 16.5, \\ \text { S3 } & =10.5, & & & \end{array}$

Treatments were arranged in a factorial design with 3 replications on the base of a Completely Randomized Design (CRD). Salty solutions were prepared by dissolving $\mathrm{NaCl}$ in distilled water at the required concentrations, since this is a common salt that adversely affects plant growth under natural conditions (Yildrim et al., 2011).

First, seeds of each genotype were surface sterilized with $5 \%$ sodium hypochlorite solution for $10 \mathrm{~min}$ and then rinsed with sterile distilled water three times, to finally be placed on filter paper into $9 \mathrm{~cm}$ diameter Petri dishes $(25$ seeds per Petri dish). In each Petri dish, $5 \mathrm{ml}$ of specific solution was added on alternate days. In 
order to avoid salt accumulation, filters were replaced in the same interval of time. Seeds were germinated in an incubator at 25 and were considered to have germinated when the emerging radical expanded to $2 \mathrm{~mm}$ (Saboora et al., 2006). After 10 days the effects of salinity treatments were studied by sampling on dry weight of shoot and root as biomass production for each treatment.

The dry weights were measured by drying the shoot and root at $75^{\circ} \mathrm{C}$ for $48 \mathrm{~h}$, to give a constant weight. Tolerance indices and stability parameters were calculated with this difference that biomass production was replaced with yield.

Tolerance indices of SSI (Fischer and Maurer, 1978), STI and GMP (Fernandez, 1992), MP and GMP (Rosielle and Hamblin, 1981) were calculated. Then six stability parameters were performed in accordance with Eberhart and Russell's (1966) the slop value $\left(b_{i}\right)$ and deviation from regression $\left(\mathrm{S}^{2}{ }_{\mathrm{di}}\right)$, Roemer's (1917) environmental variance $\left(\mathrm{S}^{2}{ }_{\mathrm{xi}}\right)$, Wricke's (1962) ecovalance $\left(\mathrm{W}_{\mathrm{i}}^{2}\right)$, Shukla's (1972) stability variance $\left(\sigma_{i}^{2}\right)$ and Verma model $(1978)$ slop values.

The division of favourable and unfavourable environments was made based on the environmental index that represents the deviation of each environmental mean from the overall mean. Unfavourable environments are those with negative or zero indices and favourable environments have positive indices, so third level of salinity treatments was determined as middle point of tow environments.

All statistical procedures were carried out using the R program (Everitt and Hothorn, 2006). Relationships among variables were determined using Spearman's correlation test, and graphs were created using STATISTICA software. In order to determinate different genotypes and their relationships, cluster analysis was applied. The cluster analysis based on Euclidean distance was performed on the basis of tolerance indices and stability parameters by using the Ward method in the most level of salinity.

\section{RESULT}

Analysis of data presented in Table 1 . showed that salt stress had adverse effect on seedling growth of barley. There were significant differences between performance barley genotypes and salinity levels. Also, there were significant difference amongst the genotype $\times$ salt stress interaction for the biomass production trait. Biomass production was decreased with increasing in salt concentration almost in all barley varieties except the genotype E that showed unchanged biomass production in second level of salinity and even more amount of that in third level of salt concentrations although their differences were not significant (Table 2). Due to significant statistical difference of genotype $\times$ salt stress interaction, a selection of genotypes with best performance in a level of salinity based on their production in other levels of salinity will not be possible. The biomass production under control condition was highest for A, C and G, whereas with the highest levels of salinity this was the case for $\mathrm{C}, \mathrm{D}$ and $\mathrm{H}$ (Table 2). 
Analysis of variance of biomass production data

Table 1

\begin{tabular}{lccccc}
\hline \multirow{2}{*}{ Parameters } & \multicolumn{5}{c}{ S.O.V } \\
\cline { 2 - 6 } & Treatment & Genotype $(\mathrm{G})$ & Salt(S) & $\mathrm{G} \times \mathrm{S}$ & Error \\
\hline DF & 44 & 8 & 4 & 32 & 90 \\
MS & $68.87^{* *}$ & $53.8^{* *}$ & $518^{* *}$ & $16.5^{* *}$ & 2.5 \\
\hline
\end{tabular}

$\mathrm{ns},{ }^{*}$ and ${ }^{* *}$ : Not significant, and significant at the $5 \%$ and $1 \%$ levels of probability, respectively

Table 2

Statistical comparison of means for genotype biomass production (mgr/plant) by Duncan's multiple range test $(\alpha=0.01)$

\begin{tabular}{|c|c|c|c|c|c|c|}
\hline \multirow{2}{*}{ Genotype } & \multicolumn{6}{|c|}{ Salt } \\
\hline & $\mathrm{S}_{1}$ & $\mathrm{~S}_{2}$ & $\mathrm{~S}_{3}$ & $\mathrm{~S}_{4}$ & $\mathrm{~S}_{5}$ & \\
\hline A & $27^{\mathrm{ab}}$ & $17.67^{\text {hijk }}$ & $15.33^{j \mathrm{klmno}}$ & $11.67^{\mathrm{opqr}}$ & $12.67^{\text {mnopq }}$ & $16.8_{\mathrm{c}}$ \\
\hline B & $24.33^{\mathrm{abcde}}$ & $19^{\text {ghij }}$ & $15.67^{\mathrm{jklmn}}$ & $13.33^{\operatorname{lmnopq}}$ & $11.67^{\mathrm{opqr}}$ & $16.9_{\mathrm{c}}$ \\
\hline $\mathrm{C}$ & $27^{\mathrm{ab}}$ & $18.33^{\text {ghijk }}$ & $17.33^{\mathrm{hijk}}$ & $15.67^{\mathrm{jklmn}}$ & $17^{\text {hijkl }}$ & $19.1_{\mathrm{ab}}$ \\
\hline $\mathrm{D}$ & $22^{\text {cdefg }}$ & $21^{\text {defgh }}$ & $20.67^{\mathrm{efgh}}$ & $14.67^{\mathrm{klmnop}}$ & $15.67^{\mathrm{jklmn}}$ & $18.9_{\mathrm{ab}}$ \\
\hline E & $18.33^{\text {ghijk }}$ & $18.33^{\text {ghijk }}$ & $20^{\text {fghi }}$ & $12.67^{\mathrm{mnopq}}$ & $11.33^{\mathrm{pqr}}$ & $16.4_{\mathrm{c}}$ \\
\hline F & $24.67^{\mathrm{abcd}}$ & $23.33^{\text {bcdef }}$ & $21^{\text {defgh }}$ & $20^{\text {fghi }}$ & $11.33^{\mathrm{pqr}}$ & $20.1_{a}$ \\
\hline G & $28^{\mathrm{a}}$ & $20.33^{\text {fghi }}$ & $18.33^{\text {ghijk }}$ & $13^{\mathrm{mnopq}}$ & $12.33^{\text {nopq }}$ & $18.4_{\mathrm{b}}$ \\
\hline $\mathrm{H}$ & $25.33^{\mathrm{abc}}$ & $18^{\text {ghijk }}$ & $18.67^{\text {ghijk }}$ & $20^{\text {fghi }}$ & $16.33^{\mathrm{ijklm}}$ & $19.6_{\mathrm{ab}}$ \\
\hline \multirow[t]{2}{*}{ I } & $20.67^{\text {efgh }}$ & $17.67^{\text {hijk }}$ & $15^{\mathrm{jklmnop}}$ & $9.67^{\mathrm{qr}}$ & $8.33^{r}$ & $14.1_{\mathrm{d}}$ \\
\hline & $24.2_{\mathrm{a}}$ & $19.3_{b}$ & $18.1_{\mathrm{c}}$ & $14.5_{\mathrm{d}}$ & $13_{\mathrm{e}}$ & \\
\hline
\end{tabular}

Values followed by different letter(s) differ significantly. Genotypes: STW82153(A), MBS8712(B), ESBYTM8910(C), 4 Shori (D), 5 Shori (E), WB7910(F), Valfajr(G), MBS8715(H) and Jo torsh(I)

Stress tolerance indices values for studied genotypes (S1 vs. S5)

\begin{tabular}{cccccccc}
\hline Rank & TOL & MP & GMP & SSI & STI & Yp & Ys \\
\hline 1 & D 6.6 & C 22.1 & C 21.5 & D 0.6 & C 0.8 & G 28.1 & C 17 \\
2 & E 6.8 & H 20.7 & H 20.2 & H 0.8 & H 0.7 & C 27.2 & H 16.3 \\
3 & H 8.9 & G 20.3 & G 18.7 & E 0.8 & G 0.6 & A 27 & D 15.6 \\
4 & C 10.2 & A19.8 & D 18.6 & C 0.8 & D 0.6 & H 25.2 & A 12.6 \\
5 & I 12.4 & D 18.9 & A 18.5 & B 1.1 & A 0.6 & F 24.7 & G 12.5 \\
6 & B 12.6 & B 18.2 & B 17.1 & A 1.2 & B 0.5 & B 24.5 & B 11.9 \\
7 & F 13.2 & F 18.1 & F 16.8 & F 1.2 & F 0.5 & D 22.2 & E 11.6 \\
8 & A 14.4 & E 15 & E 14.6 & G 1.2 & E 0.4 & I 20.6 & F 11.5 \\
9 & G 15.6 & I 14.4 & I 13 & I 1.3 & I 0.3 & E 18.4 & I 8.2 \\
\hline
\end{tabular}

$\mathrm{S} 1=4.5 \mathrm{ds} \times \mathrm{m}^{-1}, \mathrm{~S} 5=16.5 \mathrm{ds} \times \mathrm{m}^{-1}$ 
In the highest level of salinity, the best results based on stress tolerance indices (STI, TOL, SSI, MP, GMP) belonged to C, H, E and D genotypes (Table 3). Correlation coefficient tests of stress tolerance indices with Yp and Ys showed various results in different levels of salinity (Table 4).

Correlation coefficient of stress tolerance indices with Yp and Ys

\begin{tabular}{|c|c|c|c|c|c|c|c|}
\hline \multirow{2}{*}{$\begin{array}{c}\text { Stress } \\
\text { tolerance }\end{array}$} & \multicolumn{7}{|c|}{$\mathrm{S} 1\left(4.5 \mathrm{ds} \times \mathrm{m}^{-1}\right)$ vs. $\mathrm{S} 3\left(10.5 \mathrm{ds} \times \mathrm{m}^{-1}\right)$} \\
\hline & TOL & MP & GMP & SSI & STI & Yp & YS \\
\hline TOL & 1 & & & & & & \\
\hline MP & 0.31 & 1 & & & & & \\
\hline GMP & 0.19 & $0.99 * *$ & 1 & & & & \\
\hline SSI & $0.98 * *$ & 0.22 & 0.1 & 1 & & & \\
\hline STI & 0.05 & $0.95^{* *}$ & $0.97 * *$ & -0.04 & 1 & & \\
\hline Yp & $0.85^{* *}$ & $0.76^{*}$ & $0.67 *$ & $0.79 *$ & 0.56 & 1 & \\
\hline Ys & $-0.69^{*}$ & 0.46 & 0.56 & $-0.76^{*}$ & $0.67 *$ & -0.22 & 1 \\
\hline \multirow{2}{*}{$\begin{array}{l}\text { Stress } \\
\text { tolerance }\end{array}$} & \multicolumn{7}{|c|}{$\mathrm{S} 1\left(4.5 \mathrm{ds} \times \mathrm{m}^{-1}\right)$ vs. $\mathrm{S} 5\left(16.5 \mathrm{ds} \times \mathrm{m}^{-1}\right)$} \\
\hline & TOL & MP & GMP & SSI & STI & Yp & Ys \\
\hline TOL & 1 & & & & & & \\
\hline MP & 0.16 & 1 & & & & & \\
\hline GMP & -0.02 & $0.98 * *$ & 1 & & & & \\
\hline SSI & $0.89 * *$ & -0.26 & -0.43 & 1 & & & \\
\hline STI & -0.07 & $0.96^{* *}$ & $0.99 * *$ & -0.46 & 1 & & \\
\hline Yp & 0.62 & $0.87 * *$ & $0.76^{*}$ & 0.23 & $0.73^{*}$ & 1 & \\
\hline Ys & -0.43 & $0.82 * *$ & $0.91 * *$ & $-0.76^{*}$ & $0.92 * *$ & 0.43 & 1 \\
\hline
\end{tabular}

$*$,**: Significant at the $5 \%$ and $1 \%$ levels of probability respectively.

The results of five parametric stability statistics are given in Table 5. According to the Eberhart and Russell (1966) model, regression coefficient $\left(b_{i}\right)$ approximating 1.0 coupled with deviation from regression $\left(\mathrm{S}^{2}{ }_{\mathrm{di}}\right)$ of zero indicate average stability. When this is associated with high mean yield, genotypes have general adaptability and when associated with low mean yield, genotypes are poorly adapted to environments. $b_{i}$ values above 1.0 describe genotypes with higher sensitivity to environmental change (below average stability), and greater specificity of adaptability to high yielding environments. Regression coefficient decreasing below 1.0 provide a measure of greater resistance to environmental changes (above average stability) and therefore increasing specificity of adaptability to low yielding environments. The genotypes A and $\mathrm{G}$ had a higher biomass production and a coefficient values greater than one. These genotypes are sensitive to environmental changes and would be recommended for cultivation under favorable conditions. The genotypes with a $b_{i}$ value lower than one were $\mathrm{D}$ and $\mathrm{H}$ that had suitable performance under stress conditions. 
Stability parameters values of barley genotypes

Table 5

\begin{tabular}{|c|c|c|c|c|c|c|c|c|c|c|}
\hline $\begin{array}{c}\text { Geno- } \\
\text { type }\end{array}$ & $b_{i}$ & $\operatorname{rank} b_{i}$ & $\mathrm{~S}_{\mathrm{di}}^{2}$ & $\operatorname{rankS}_{\mathrm{di}}^{2}$ & $\mathrm{~W}_{\mathrm{i}}^{2}$ & $\operatorname{rank} \mathrm{W}^{2}{ }_{\mathrm{i}}$ & $\mathrm{S}^{2} \mathrm{i}$ & $\operatorname{rank} \mathrm{S}_{\mathrm{i}}^{2}$ & $\sigma_{i}^{2}$ & $\operatorname{rank} \sigma_{i}^{2}$ \\
\hline A & 1.355 & 2 & 3.66 & 5 & 20.96 & 6 & 38.15 & 8 & 5.94 & 6 \\
\hline B & 1.113 & 4 & 0.7 & 1 & 3.24 & 1 & 24.6 & 5 & 0.24 & 1 \\
\hline $\mathrm{C}$ & 0.914 & 6 & 6.65 & 7 & 20.22 & 5 & 20.97 & 4 & 5.7 & 5 \\
\hline $\mathrm{D}$ & 0.712 & 7 & 3.25 & 4 & 16.17 & 3 & 12 & 2 & 4.4 & 3 \\
\hline $\mathrm{E}$ & 0.676 & 8 & 8.43 & 8 & 33.01 & 9 & 14.95 & 3 & 9.82 & 9 \\
\hline $\mathrm{F}$ & 0.992 & 5 & 10.47 & 9 & 31.65 & 8 & 26.7 & 6 & 9.38 & 8 \\
\hline G & $1.45^{*}$ & 1 & 0.76 & 2 & 17.37 & 4 & 40.66 & 9 & 4.79 & 4 \\
\hline $\mathrm{H}$ & 0.62 & 9 & 5.52 & 6 & 28.02 & 7 & 11.49 & 1 & 8.21 & 7 \\
\hline I & 1.18 & 3 & 1.55 & 3 & 7.1 & 2 & 27.9 & 7 & 1.49 & 2 \\
\hline
\end{tabular}

According to Wricke's stability parameter $\left(\mathrm{W}^{2} \mathrm{i}\right)$, genotypes with the smallest ecovalance values are considered stable. The $\left(\mathrm{W}^{2} \mathrm{i}\right)$ was lowest for genotypes $\mathrm{B}$, $\mathrm{I}$ and highest for $\mathrm{F}, \mathrm{E}$ and $\mathrm{H}$. The stability variance $\left(\sigma^{2} \mathrm{i}\right)$ revealed that the genotypes B, I and D had the smallest variance across the environments and were stable, while the genotypes $\mathrm{H}, \mathrm{F}$ and $\mathrm{E}$ had the largest $\left(\sigma^{2} \mathrm{i}\right)$ and were unstable. Best performance in favourable environments belonged to $A, G$ and $C$ but with increase in salt concentration $\mathrm{C}$ and $\mathrm{H}$ genotypes were appeared better than others (Table 6).

Table 6

Regression coefficient of Verma model for favorable and unfavorable environments

\begin{tabular}{ccc}
\hline \multirow{2}{*}{ Genotype } & \multicolumn{3}{c}{ Regression coefficient } \\
\cline { 2 - 3 } & Favorable & Unfavorable \\
\hline A & 1.84 & 0.73 \\
B & 1.33 & 0.78 \\
C & 1.68 & 0.14 \\
D & 0.21 & 1.16 \\
E & -0.24 & 1.8 \\
F & 0.5 & 1.6 \\
G & 1.61 & 1.18 \\
H & 1.2 & 0.3 \\
I & 0.87 & 1.32 \\
\hline
\end{tabular}

The number of clusters was determined by the cluster sum of squares in "Elbow criterion" plot. The cluster analysis showed that the genotypes identified based on indices and stability parameters can be divided into three groups (Fig. 3). 


\section{DISCUSSION}
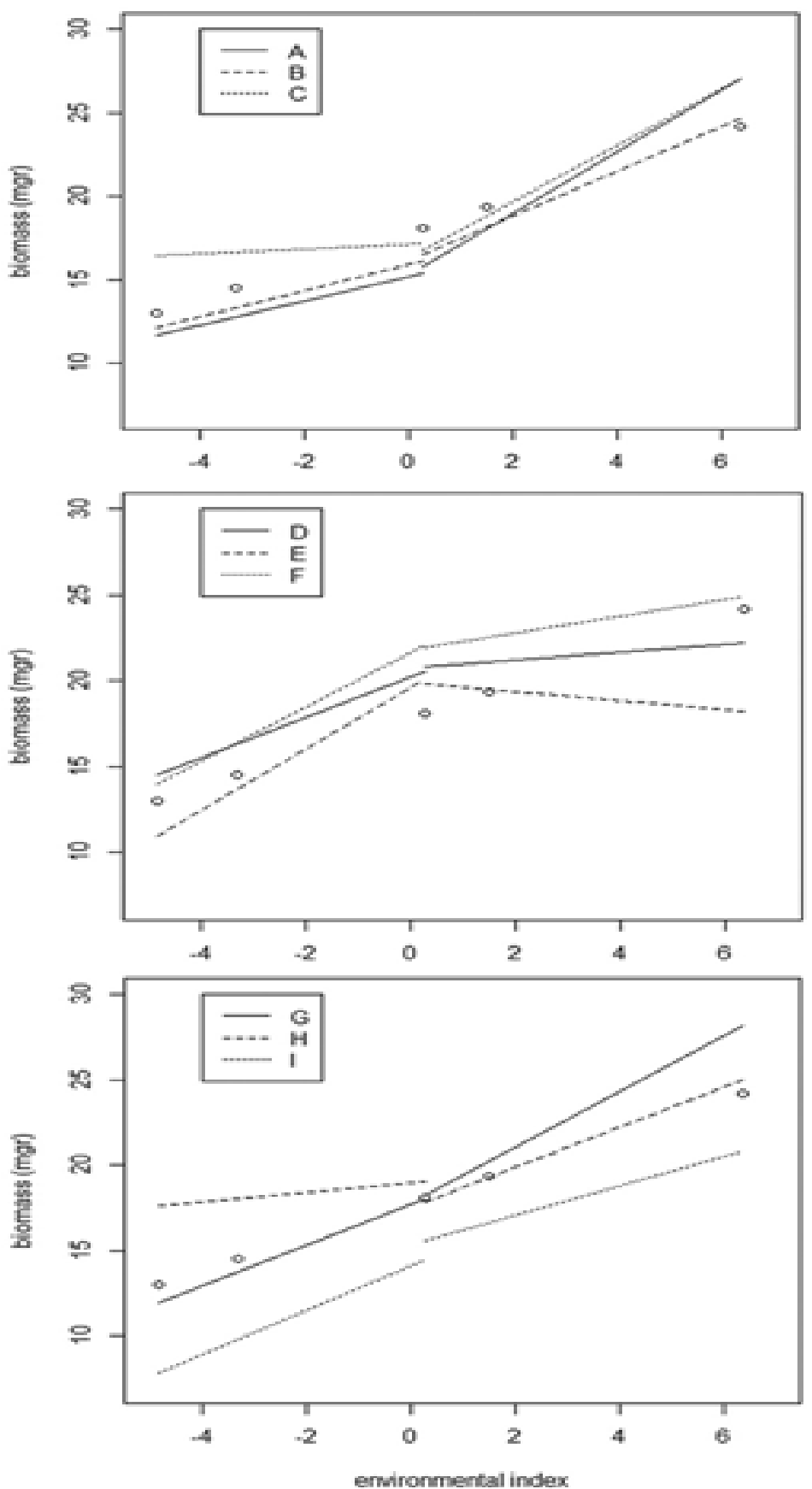

Fig. 1. Dispersion between Yp, Ys and tolerance indices, A: S1 $\left(4.5 \mathrm{ds} \times \mathrm{m}^{-1}\right)$ vs. $\mathrm{S} 3\left(10.5 \mathrm{ds} \times \mathrm{m}^{-1}\right)$, B: $\mathrm{S} 1\left(4.5 \mathrm{ds} \times \mathrm{m}^{-1}\right)$ vs. $\mathrm{S} 5\left(16.5 \mathrm{ds} \times \mathrm{m}^{-1}\right)$. 
The result of reduction of dry matter production in the present study are in agreement with Greenway and Munns (1980) who showed this reduction in weights with increasing salinity may be due to limited supply of metabolites to young growing tissues, because metabolic production is significantly perturbed at high salt stress, either due to the low water uptake or toxic effect of $\mathrm{NaCl}$. These results indicate that genetic variation exists among barley genotypes in terms of early seedling growth rate under salt stress condition. According to several reports, a genotype with a highly appropriate response to a certain salinity level cannot necessarily be considered a tolerant genotype.

Instead, a genotype that shows a low yield difference between normal and stress conditions is called tolerant. Fernandez (1992), who studied the yield of genotypes in normal and stress environments, has divided them into four groups: genotypes that have high yield in stress and non-stress environments (group A), genotypes that have a high yield in non-stress environments only (group B), genotypes that have high yield in stress environments (group C) and genotypes that have low yields in stress and non-stress environments (group D).

As an appropriate measure to separate the first group from the other groups, an analysis of the correlation between responses under stress and non-stress conditions as well as quantitative stress tolerance indices, superior indices and consequently genotypes, was used. Generally, indices having high correlations with plant response in stress and non-stress conditions are introduced as the best ones (Ashraf et al., 2015; Ganjeali et al., 2011). In all of the salinity levels correlation between Yp and Ys was very weak, so selection based on genotype response in one of conditions for the anticipation of its performance in other condition will be powerless. As is shown in Fig. 1-A, in spite of SSI high correlation with Yp and Ys there is no determined trend for introducing the genotypes with the best reply in both conditions based on SSI. Nevertheless, according to Fig.1-B , STI can be a suitable index for this proposition.

Plant breeders have a full hand of methods for the analyses of genotype yield adaptability and stability to help in the difficult task of identifying superior cultivars in the presence of genotype $\times$ environment interaction (GEI). GEI is important source of variation in any crop and the term stability is sometimes used to characterize a genotype, which shows a relatively constant yield, independent of changing environmental conditions. On the basis of this idea, genotypes with a minimum variance for yield across different environments are considered stable. This idea of stability may be considered as a biological or static concept of stability (Becker and Leon, 1988). This concept of stability is not acceptable to most breeders and agronomists who would prefer an agronomic or dynamic concept of stability; therefore they prefer genotypes with high mean yields and the potential to respond to agronomic inputs or better environment conditions. In the dynamic concept of stability, it is not required that the genotype response to environmental conditions should be equal for all genotypes (Becker and Leon, 1988).

Most of the stability methods indicated that the genotype D was the most phenotypically stable with high mean yield (Table 5). An ideal genotype possesses:

1) high yield performance; 
2) low sensitivity to adverse conditions and

3 is capable of responding positively when environmental conditions are improved (Ferreira and Demetrio, 2006). On this fact the ideal genotype has a regression coefficient smaller than 1 for unfavourable environments and greater 1 for favourable environments. Desirable genotypes have concave pattern for regression linear models and $\mathrm{C}$ and $\mathrm{H}$ genotypes showed such pattern across the levels of salinity (Fig. 2).
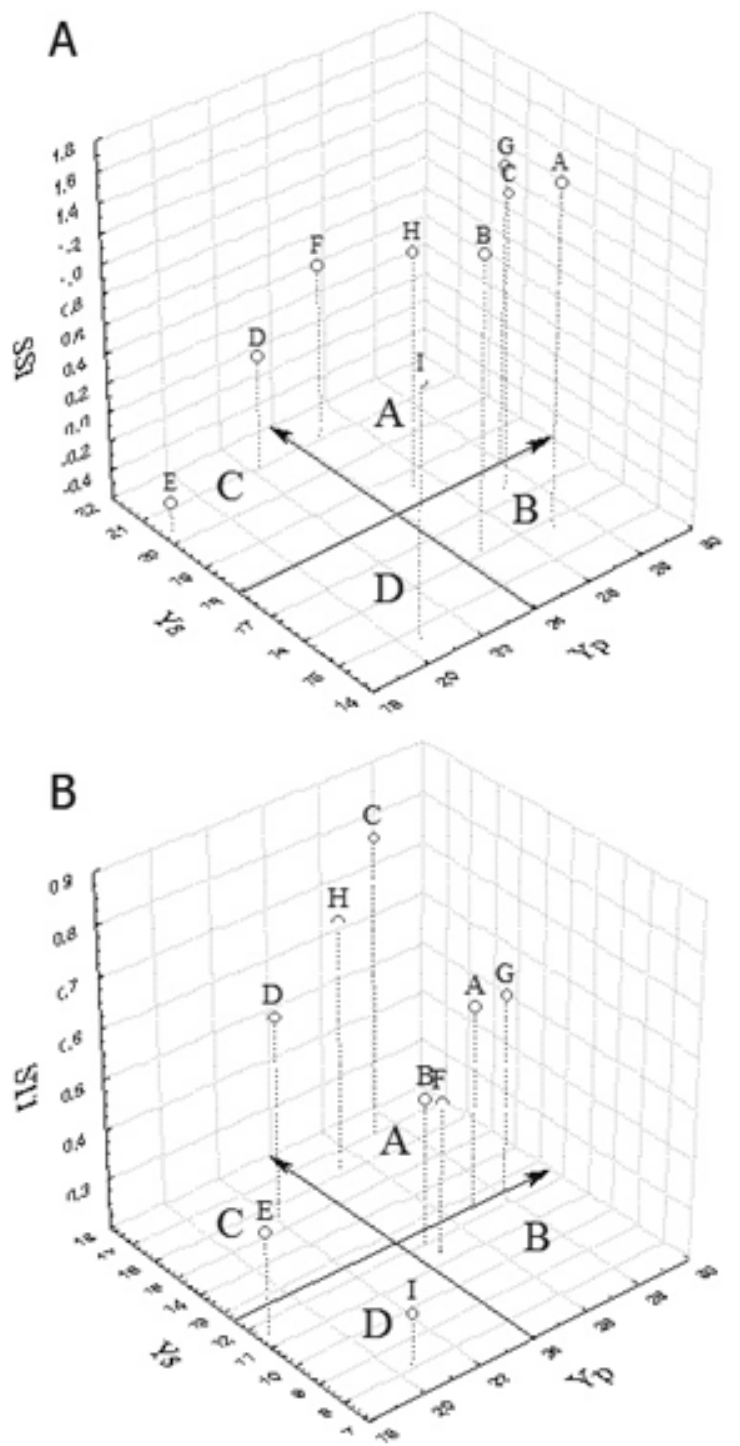

Fig. 2. Performance of barley genotypes across salinity levels based on Verma regression model 
In this study, cluster analysis determined that genotypes with high STI, MP and GMP values (Table 7), can be considered the most tolerant and desirable genotypes for both growth conditions. On the other hand it revealed that tolerant genotypes showed the least stability based on mostly of stability parameters. It can be because of variation in their potential for biomass production under different conditions and showed the importance of selection for genotypes performance in both normal and stress environments.

Table 7

Differences of genotype tolerance indices and stability parameters by mean at S5 level of salinity

\begin{tabular}{ccccccc}
\hline \multirow{2}{*}{ Genotypes } & \multicolumn{7}{c}{ Property } \\
\cline { 2 - 7 } & Yp & Ys & TOl & MP & GMP & SSI \\
\hline A & 27 & 12.67 & 14.4 & 19.8 & 18.5 & 1.2 \\
B, G, I & 24.33 & 10.77 & 13.53 & 17.63 & 16.27 & 1.2 \\
C, D, E, F, H & 23.46 & 14.33 & 9.14 & 18.96 & 18.34 & 0.84 \\
\hline Genotypes & STI & $\mathrm{b}_{\mathrm{i}}$ & $\mathrm{S}^{2}{ }_{\mathrm{di}}$ & $\mathrm{W}_{\mathrm{i}}{ }_{\mathrm{i}}$ & $\mathrm{S}^{2}{ }_{\mathrm{i}}$ & $\sigma_{\mathrm{i}}$ \\
\hline $\mathrm{A}$ & 0.6 & 1.355 & 3.66 & 50.96 & 38.15 & 5.94 \\
B, G, I & 0.47 & 1.24 & 1 & 9.23 & 31.05 & 2.17 \\
C, D, E, F, H & 0.6 & 0.78 & 6.86 & 25.81 & 17.22 & 7.5 \\
\hline
\end{tabular}

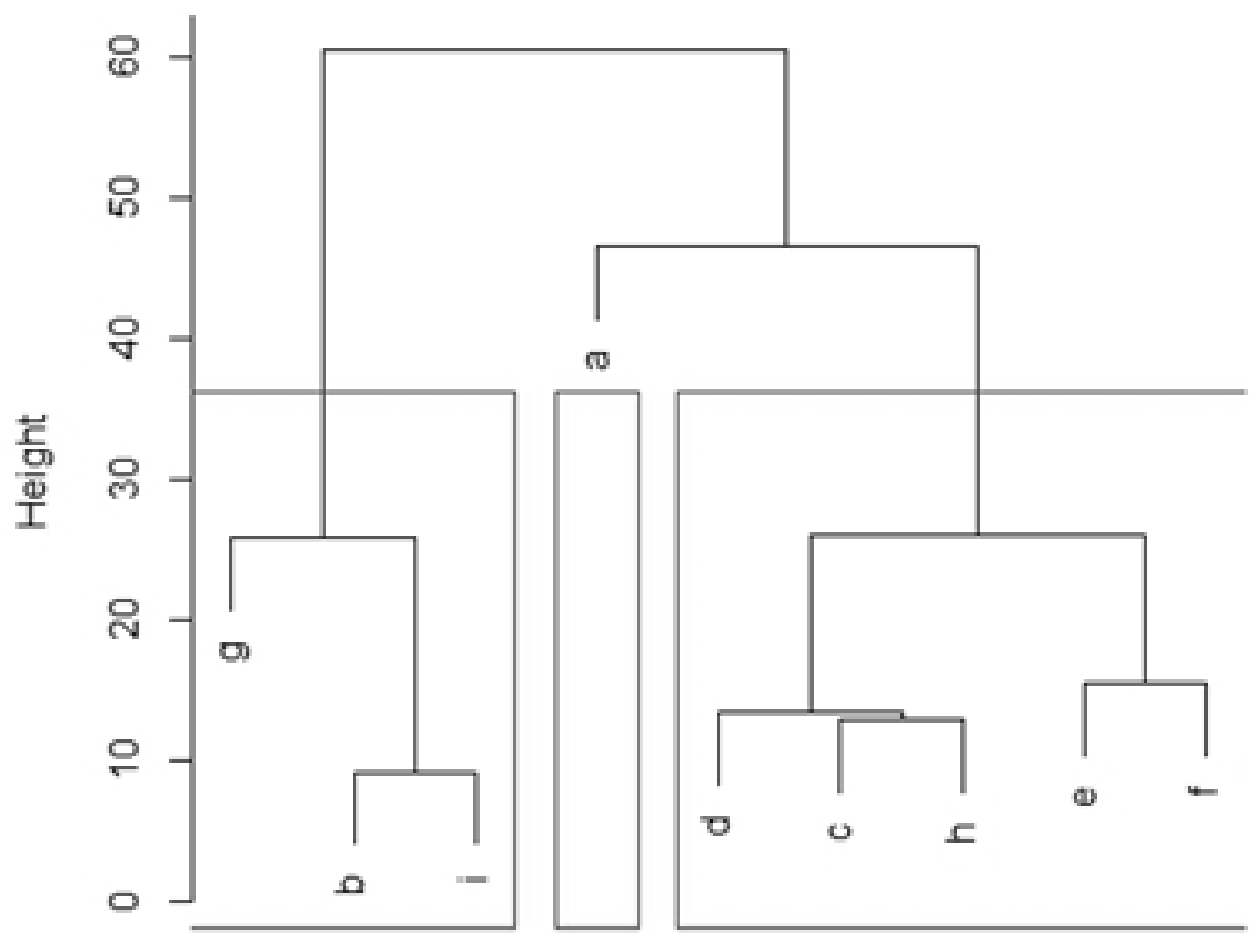

Fig. 3. Cluster analysis of barley genotypes based on tolerance indices and stability parameters 


\section{CONCLUSION}

The results from this study are very useful for the planning of further barley breeding programs. Salt stress significantly affected the performance of barley genotypes. GMP, MP and STI were more suitable indices for selecting barley genotypes tolerant to salt stress.

The barley selection using these indices can be useful for identifying a cultivar with desirable establishment under both stress and non-stress conditions. Several stability measures that have been used in this study quantified stability of genotypes with respect to yield, stability or both. So both yield and stability should be considered simultaneously to exploit the useful effects of GEI and to refine selection of genotypes. Yet, among all genotypes the WB7910, ESBYTM8910 and MBS8715 showed the best performance in the study.

\section{REFERENCE}

Ashraf, A., Abd el Shafi M. A., Gheith E. M. S., Suleiman H. S., et al., 2015, Using different statistical procedures for evaluation drought tolerance indices of bread wheat genotypes, Adv. Agric. Biol., 4(1):19-30 Becker H.C., Leon J. et al., Stability analysis in plant breeding, 1988. Plant Breed. 101: 1-23.

Bernardo M., Enrique T., Jose L. G., et al., 2006. Effect of $\mathrm{NaCl}$ salinity in the genotypic variation of cowpea (Vigna unguiculata) during early vegetative growth, Scientia Horticulturae , 108:423-431

Betran F.J., Beck D., Banziger M., Edmeades G. O., et al., 2003, Genetic analysis of inbred and hybrid grain yield under stress and non-stress environments in tropical maize, Crop. Sci., 43:807-817

Bradshaw A.D., 2006, Unravelling phenotypic plasticity—why should we bother? N. Phytol,170:644-648

Eberhart S.A., Russell W.A., et al., 1966, Stability parameters for comparing varieties, Crop Sci., 6:36 - 40.

Everitt B., Hothorn T., 2006, A handbook of statistical analyses using R. Chapman \& Hall/CRC. Taylor \& Francis Group.

Fernandez G. C. J., 1992, Effective selection criteria for assessing stress tolerance. In: Kuo C. G. (ED,), Proceedings of the International Symposium on Adaptation of Vegetables and Other Food Crops in Temperature and Water Stress, Publication, Tanian, Taiwan.

Ferreira, D., Demetrio C., et al., 2006. Statistical models in agriculture: biometrical methods for evaluating phenotypic stability in plant breeding. CERNE. Vol $12: 373-388$

Fischer R.A., Maurer R., et al., 1978, Drought resistance in spring wheat cultivars. Part1: grain yield response, Aust. J. Agric. Res. 29:897-912

Fritsche R., Borém A., 2005, Plant breeding for abiotic stress tolerance, Springer Heidelberg New York Dordrecht London.

Ganjeali A., Porsa H., Bagheri A., et al., 2011, Assessment of Iranian chickpea (Cicer arietinum L.) germplasms for drought tolerance, Agr. Water Manage. 98:1477-1484

Giancarla V., Madosa E., Sumalan R., Adriana C., Cerasela P., et al., 2012. Evaluation of some indirect indices to identify drought tolerance in barley. J. Hort. For Biotech. 16: 239-241.

Greenway H., Munns H., et al., 1980, Mechanisms of salt tolerance in nonhalo-phytes. Annu. Rev. Plant Physiol. 31, 149-190

Katerji N., van Hoorn J.W., Hamdy A., Mastrorilli M., et al., 2006, Classification and salt tolerance analysis of barley varieties, Agricultural Water Management, 85:84-92

Mariangela D., Montemurro F., et al., 2015, Effectiveness of organic wastes as fertilizer and amendments in salt-affected soils. Agriculture, 5:221-230.

Muhammad J., Deog B. L., Kwang Y.J., Muhammad A., Sheong C., Eui S.R., et al., 2006, Effect of salt $(\mathrm{NaCl})$ stress on germination and early seedling growth of four vegetables species, Central European Agriculture Journal. 2:273-282.

Nasser, Sh., Nisar A., Ashraf M., et al., Effect of salt stress on germination and seedling growth of barley (Hordeum voulgar L.), Pak. J. Biol. Sci. 2001, 4(3):359-360

Rosielli A.A., Hamblin J., et al.,1981, Theoretical aspects of selection for yield in stress and non-stress environment, Crop. Sci. 21:943-946

Saboora A., Kiarostami K., Behroozbayati F., et al., 2006, Salinity $(\mathrm{NaCl})$ tolerance of wheat genotypes at germination and early seedling growth, Pakistan Journal of Biological Sciences. 9(11):2009-2021

Shukla G.K., et al., 1972, Some aspects of partitioning genotype-environmental components of variability, Heredity, 29: 237-245 
Verma M. M., Chahal G. S., Murty B. R., et al., 1978, Limitations of conventional regression analysis: a proposed modification. Theoretical and Applied Genetics, 52:89-91

Wricke G., et al., 1962, On a method of understanding the biological diversity in field research. Z. Pfl.-zucht. 47: 92-96.

Yildrim E., Karlidag H., Dursun A., et al., 2011, Salt tolerance of Physalis during germination and seedling growth. Pak. J. Bot., 43(6):2673-2676 